\title{
Inhibition of basal cell carcinoma cells by cold atmospheric plasma-activated solution and differential gene expression analysis
}

\author{
XINGYU YANG ${ }^{1}$, CHUNJUN YANG $^{1}$, LIYUN WANG $^{1}$, ZHICHENG CAO $^{1}$, \\ YUAN WANG $^{2}, \mathrm{CHENG} \mathrm{CHENG}^{3}$, GUOPING ZHAO $^{4}$ and YEZHAO \\ ${ }^{1}$ Department of Dermatology, The Second Affiliated Hospital, Anhui Medical University, Hefei, Anhui 230601; \\ ${ }^{2}$ Department of Orthopaedics, First Affiliated Hospital of Anhui Medical University, Hefei, Anhui 230022; \\ ${ }^{3}$ The Institute of Plasma Physics; ${ }^{4}$ Anhui Province Key Laboratory of Environmental Toxicology and Pollution \\ Control Technology, Hefei Institutes of Physical Science, Chinese Academy of Sciences, Hefei, Anhui 230031; \\ ${ }^{5}$ Teaching and Research Section of Nuclear Medicine, Anhui Medical University, Hefei, Anhui 230032, P.R. China
}

Received September 21, 2019; Accepted January 21, 2020

DOI: 10.3892/ijo.2020.5009

\begin{abstract}
Basal cell carcinoma is a common skin tumor. Cold atmospheric plasma (CAP) has attracted increasing attention for its antitumor effects. The aim of the present study was to investigate the effects and related mechanisms of two CAP-activated solutions on the TE354T basal cell carcinoma and $\mathrm{HaCat}$ keratinocyte cell lines. Plasma-activated solution (PAS) was prepared by CAP irradiation of DMEM and PBS. TE354T cells were treated with PAS in vitro and the effect on cell viability was evaluated by an MTT assay. The apoptosis rate was detected by Annexin V/propidium iodide staining. Furthermore, western blotting and RNA-sequencing were performed. The present results demonstrated that PAS induced apoptotic signaling in basal cell carcinoma cells, and that this effect was associated with the activation of the MAPK signaling pathway. Therefore, the present study demonstrated that PAS may serve as a novel treatment for basal cell carcinoma.
\end{abstract}

\section{Introduction}

Basal cell carcinoma (BCC) is the most common skin tumor worldwide, accounting for $\sim 80 \%$ of non-melanoma skin cancer cases (1-3). BCC is generally well-differentiated

Correspondence to: Dr Chunjun Yang, Department of Dermatology, The Second Affiliated Hospital, Anhui Medical University, 678 Furong Road, Hefei, Anhui 230601, P.R. China E-mail: yangchunjun9@163.com

Abbreviations: ATM, ataxia telangiectasia-mutated; BCC, basal cell carcinoma; CAP, cold atmospheric plasma; DEG, differentially expressed gene; DSB, double strand break; PAS, plasma-activated solution; RNS, reactive nitrogen species; ROS, reactive oxygen species

Key words: CAP, PAS, BCC, ROS, RNA-sequencing, MAPK and exhibits a slow growth pattern, often resulting in skin nodules and ulcers, and metastasis in rare cases (4). The most appropriate treatment for $\mathrm{BCC}$ is determined according to the size and location of the tumor, and the degree of infiltration. Interventions currently include surgical resection, photodynamic therapy and molecular targeted therapy $(5,6)$. Previous studies demonstrated that the increased incidence and mortality of BCC are due to the decreased effectiveness of current treatments $(3,7)$. Therefore, the development of safe and reliable treatment strategies to reduce the mortality rate is required.

Cold atmospheric plasma (CAP) is a near room temperature ionized gas composed of charged particles, neutral particles and electrons (8). In the past two decades, CAP has been demonstrated to stimulate coagulation and to promote wound healing $(9,10)$. An increasing number of studies have demonstrated the significant anticancer effect of CAP in several cancer cell lines, including glioblastoma, malignant melanoma, breast cancer and lung cancer cell lines, in vitro $(11,12)$. From research on the anti-cancer mechanism of CAP, it was identified that among some reactive oxygen species (ROS) and reactive nitrogen species (RNS) produced by CAP, ROS, such as hydrogen peroxide, hydroxide, ozone and peroxide ion, play a major role in inducing tumor cell apoptosis $(13,14)$. A number of previous in vitro experiments demonstrated that intracellular ROS concentrations were significantly increased following treatment with CAP, resulting in damage to the intracellular antioxidant system $(15,16)$. This phenomenon was also observed in a previous study (17). There are currently two different perspectives regarding the mechanisms underlying this phenomenon. One is that ROS originating from CAP enter the cells via transmembrane transporters and directly disrupts cellular homeostasis due to the increased concentration of ROS, eventually leading to apoptosis. Alternatively, activated plasma may trigger the expression of a series of signaling molecules in the cells by acting on related protein targets on the cell membrane $(18,19)$. Either mechanism will lead to an imbalance between intracellular ROS and cell defense systems, leading to apoptosis. 
CAP comes into contact with the solution medium to produce physical and chemical changes, and further acts on cells to promote apoptosis in vitro (20). Based on this phenomenon, the anticancer effect of CAP activating solution has gradually been recognized (21-23). Compared with CAP direct irradiation, CAP activating solution has the advantage of convenient storage and transportation. The media used to prepare the plasma activating solution (PAS) must be biocompatible, and include cell culture medium, PBS and Ringer's equilibrium solution $(21,24)$. Yan et al (25) identified that CAP-stimulated medium and CAP-stimulated buffered solution exerted anticancer effects on pancreatic adenocarcinoma and glioblastoma cells in vitro. In addition, the dilution of the solution is an important factor that affects the anticancer effect (25). Tanaka et al (24) observed that plasma-activated Ringer's solution exhibited good anticancer effects in vitro and in vivo. These previous results demonstrated significant progress in the use of PAS in clinical applications.

Ishaq et al (26) identified that CAP selectively induced cancer by stimulating the oxidative stress-induced tumor necrosis factor (TNF)-apoptosis signal regulating kinase 1 (ASK1)-JNK/p38-caspase-3/7 apoptotic pathway in melanoma. Furthermore, CAP-induced NADPH oxidases generated intracellular ROS, which induced apoptosis in colorectal cancer cells in vitro by activating the ASK1-mediated apoptotic pathways (19). The CAP-induced apoptotic pathway in cancer cells is triggered by DNA and mitochondrial damage (27). The majority of tumor cells show different degrees of DNA double strand breaks (DSBs) after treatment with CAP, and ataxia telangiectasia-mutated (ATM) is an important marker of DSBs. This factor activates several cell cycle arrest-associated proteins, including p53, as well as the expression of apoptotic signals through phosphorylation (28). The activation of p53 expression has been demonstrated in a variety of CAP-treated cancer cell lines $(16,29)$.

MAPKs are a group of serine-threonine protein kinases that are activated by different extracellular stimuli, including cytokines, neurotransmitters, hormones and cellular stress (30). MAPKs can be divided into four subfamilies: ERKs, p38,c-JNKs and ERK5, of which p38 plays a major role in mediating inflammation and apoptosis (30-32). In the present study, the BCC cell line TE354T was used to evaluate the effect of DMEM and PBS on proliferation after treatment with CAP. Furthermore, the changes in expression of factors in related apoptotic pathways were detected by RNA-sequencing (RNA-seq) technology. Differential expression analysis was performed on CAP-treated TE354T cells to identify changes in the MAPK and TNF pathways in PAS-induced TE354 cell apoptosis.

\section{Materials and methods}

Cell culture. The TE354T BCC and HaCaT keratinocyte cell lines were acquired from The American Type Culture Collection, and were maintained in DMEM/High Glucose (HyClone; GE Healthcare Life Sciences; pH 7.0-7.4; buffer salt including sodium phosphate monobasic, sodium bicarbonate and HEPES) with 10\% FBS (Gibco; Thermo Fisher Scientific, Inc.; $100 \mathrm{U} / \mathrm{ml}$ penicillin and $100 \mathrm{mg} / \mathrm{ml}$ streptomycin (Gibco; Thermo Fisher Scientific, Inc.). Cells were cultured at $37^{\circ} \mathrm{C}$ and $5 \% \mathrm{CO}_{2}$ in a humidified environment.
Preparation of CAP activation liquid. CAP equipment was provided by The Institute of Plasma Physics, Chinese Academy of Sciences (Fig. 1). The air plasma device includes a DC voltage input, a copper rod array and a ballast resistor. The electrode consists of six arrays of thin copper rods with a radius of $1 \mathrm{~mm}$. The ballast resistors are $30 \Omega$, and the discharge current is limited to $\sim 5 \mathrm{~mA}$. The device is activated by a $10-\mathrm{kV}$ DC voltage and generates plasma through a copper rod electrode. DMEM or PBS was added to a $35-\mathrm{mm}$ cell culture dish and irradiated with plasma to prepare the PAS. Each dish was filled with $2 \mathrm{ml}$ liquid (DMEM or PBS), the plasma electrode was placed $\sim 10 \mathrm{~mm}$ from the liquid surface, and plasma activation liquids of different concentrations were prepared by irradiation for different times (60, 120, 180, 240 and $300 \mathrm{sec}$ ). The doses of plasma-activated liquid are defined as the different processing times of the liquid under the same discharge parameters. The prepared activated solution was placed in an ice water bath or stored at $4^{\circ} \mathrm{C}$ for further experiments.

Cell morphology. TE354T cells were seeded in 6-well plates ( $2 \times 10^{5}$ cells per well) and incubated at constant temperature for $24 \mathrm{~h}$. The medium was aspirated and $2 \mathrm{ml}$ of $180 \mathrm{sec}$ plasma-activated DMEM solution was added to each well for incubation for 6 and $12 \mathrm{~h}$. The morphological changes of the cells were observed directly under a light microscope (magnification, x400). A Hoechst 33342 Staining kit was purchased from Beyotime Institute of Biotechnology. The sterilized coverslips were placed in 6-well plates and inoculated with TE354T cell culture. After the cells had grown to $50-80 \%$ of the coverslip area, the medium was aspirated and the cells were treated with $2 \mathrm{ml} 180 \mathrm{sec}$ plasma-activated DMEM solution for $2 \mathrm{~h}$. DMEM was aspirated again and the fixing solution (cat. no. C0003-1; Beyotime Insitute of Biotechnology) was added at $4^{\circ} \mathrm{C}$ for $10 \mathrm{~min}$. Subsequently, the cells were rinsed twice with PBS and $0.5 \mathrm{ml}$ Hoechst 33342 staining solution was added for incubation at room temperature for $5 \mathrm{~min}$ in the dark. The cells were washed twice with PBS and imaged under a fluorescent microscope for observation (magnification, $\mathrm{x} 1,000)$. The images were taken using an IX-71 Olympus microscope (Olympus Corporation).

Cell viability assay. Cell viability was measured by an MTT assay. All experiments used logarithmic growth phase cells collected by digestion, which were counted and inoculated in a 96-well culture plate for $24 \mathrm{~h}(10,000$ cells; $100 \mu \mathrm{l}$ culture medium per well). The cells were fully adherent at the start of experimental treatment. The cells were stimulated with plasma-activated fluid for $2 \mathrm{~h}$. Thereafter, the activation fluid was replaced with fresh DMEM and incubation was continued for 24,48 or $72 \mathrm{~h}$. In the 96-well plates, $100 \mu \mathrm{l}$ MTT solution was added to each well for $4 \mathrm{~h}$. Thereafter, the formazan was dissolved in DMSO and the absorbance was measured at $570 \mathrm{~nm}$ using a microplate reader (SpectraMax i3x; Molecular Devices, LLC).

Detection of intracellular ROS. An ROS assay kit was purchased from Beyotime Institute of Biotechnology. HaCat and TE354T cells in the logarithmic growth phase were inoculated on 96-well culture plates (10,000 cells per well), 
A
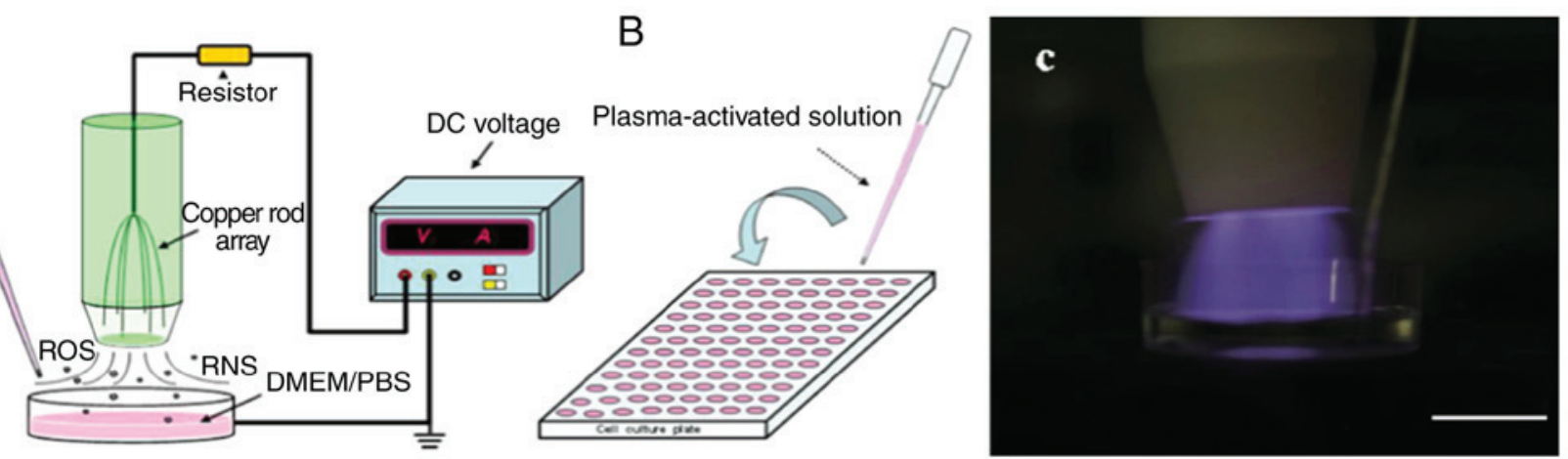

Figure 1. Schematic diagram of the CAP equipment used in the present study. (A) DMEM and PBS were active with CAP. (B) Transfer plasma-activated solution to culture plates with cells. (C) CAP equipment working in dark field. Scale bar, $10 \mathrm{~mm}$. CAP, cold atmospheric plasma; RNS, reactive nitrogen species; ROS, reactive oxygen species.

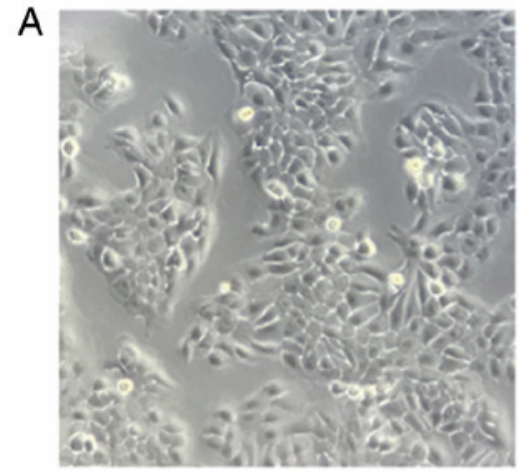

$\mathrm{Oh}$

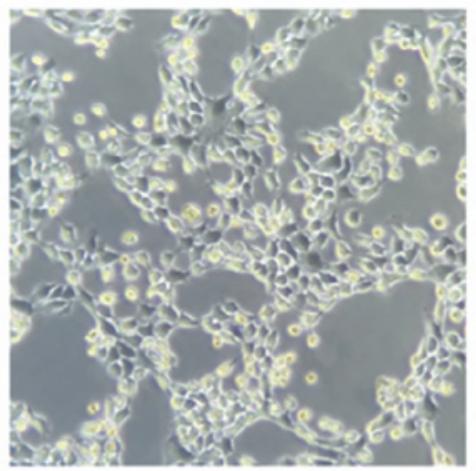

$6 \mathrm{~h}$ later

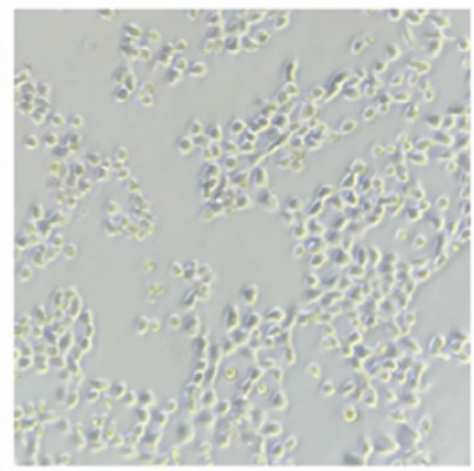

$12 \mathrm{~h}$ later

\section{B}

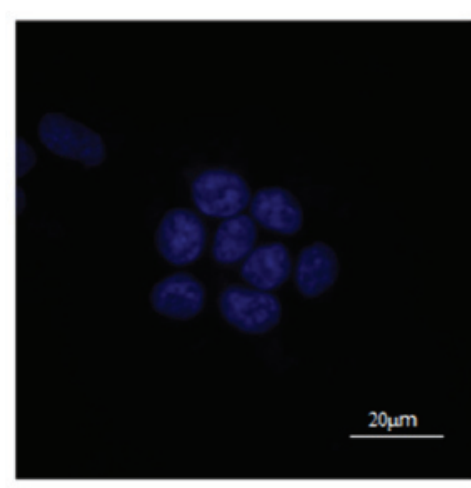

Con

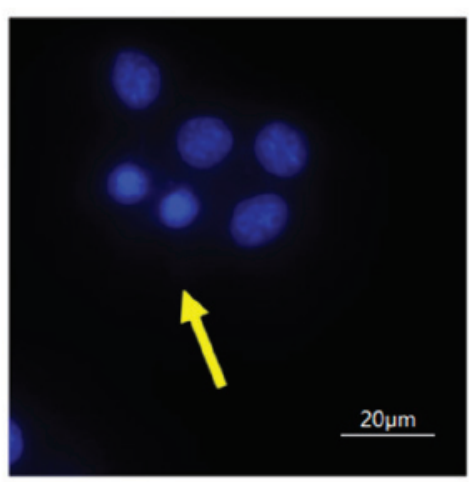

Treated

Figure 2. Morphological changes in TE354T cells after treatment with plasma-activated solution. (A) After 6 and 12 h of treatment, shrinkage of the cell membrane and partial cell detachment of adherent growth were observed. Magnification, $x 400$. (B) As indicated by the arrow, the nuclei of treated cells shrunk after treatment and showed brighter blue fluorescence. Scale bar, $20 \mu \mathrm{m}$. con, control.

and the experiment was performed after the cells were completely adherent. Cells were loaded with the fluorescent probe dichloro-dihydro-fluorescein diacetate and stimulated with plasma-activated DMEM or PBS, and changes in the concentration of ROS were measured after $2 \mathrm{~h}$. Fluorescence was measured using a fluorescence plate reader (SpectraMax i3x; Molecular Devices) at an excitation wavelength of $488 \mathrm{~nm}$ and an emission wavelength of $525 \mathrm{~nm}$ to calculate intracellular ROS levels.

Reactive species and $\mathrm{pH}$ in solution. $\mathrm{A}_{2} \mathrm{O}_{2}$ assay kit was purchased from Beyotime Institute of Biotechnology. The cell-free DMEM and PBS solutions were placed in 2-ml culture dishes, and were exposed to CAP treatment for $60,120,180,240$ and $300 \mathrm{sec}$, respectively. $\mathrm{H}_{2} \mathrm{O}_{2}$ detection reagent was added and a microplate reader (SpectraMax i3x; Molecular Devices) was used to measure A560 to calculate the $\mathrm{H}_{2} \mathrm{O}_{2}$ concentration in the liquid. The $\mathrm{pH}$ changes in different experimental groups were detected using a $\mathrm{pH}$ meter. $\mathrm{NO}_{3}{ }^{-}$in the PBS after plasma treatment was evaluated using PhotoLab 6100 (Merck KGaA) with nitrate detection kit (Merck KGaA).

Apoptosis assay. The Annexin V-FITC/propidium iodide (PI) apoptosis kit was purchased from Best-Bio(http://bestbio.bioon. 


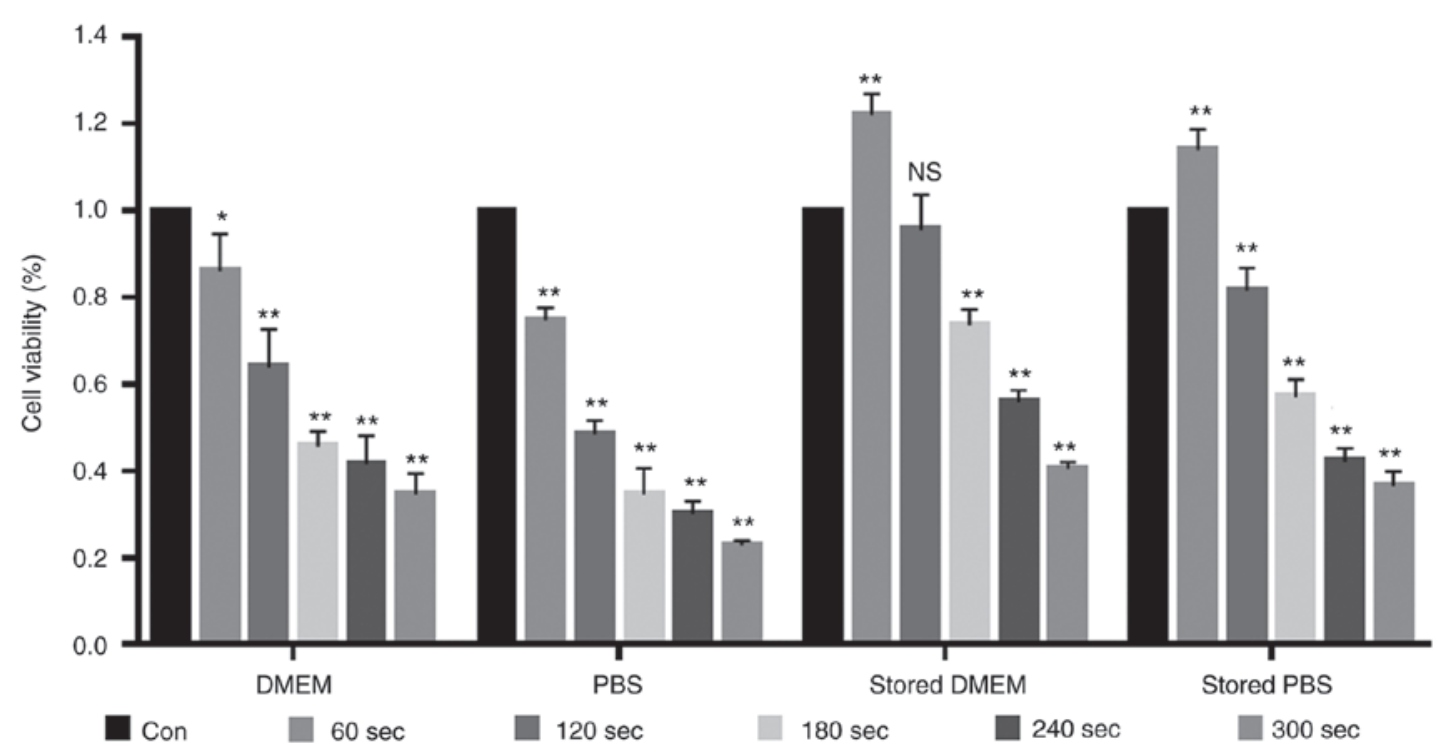

Figure 3. TE354T cells cultured under the same conditions were treated with freshly prepared PAS and PAS stored for 24 h. Cell viability of each group was measured by an MTT assay. Data are presented as the mean $\pm \mathrm{SD}$ of three independent experiment. ${ }^{*} \mathrm{P}<0.05,{ }^{* * *} \mathrm{P}<0.01$ vs. respective con. PAS, plasma-activated solution; con, control; NS, not significant.

com.cn/), and a flow cytometer was provided by The Institute of Technology Biology, Chinese Academy of Sciences. Cells were innoculated in 6-well plates and were cultured until fully adherent, and then stimulated for $2 \mathrm{~h}$ in PAS; thereafter, the medium was replaced with fresh medium and samples were placed in the incubator for $24 \mathrm{~h}$. The cells were collected for staining. Cells were suspended in Annexin V-FITC binding solution at a concentration of $\sim 1 \times 10^{6} / \mathrm{ml}$. Subsequently, $5 \mu 1$ Annexin V-FITC staining solution was added for incubation for $15 \mathrm{~min}$. A total of $10 \mu \mathrm{l}$ PI staining solution was then added for incubation for $5 \mathrm{~min}$, protected from light at $2-8^{\circ} \mathrm{C}$. The apoptosis rate of each group of cells was analyzed using a flow cytometer (BD Biosciences). The data were analyzed using FlowJo software (v10.0.7; FlowJo LLC).

Western blotting. Western blot analysis was performed at 0 , 3, 6 and $12 \mathrm{~h}$ after treating the cells with PAS. The cells were harvested by trypsinization and the resulting cell suspension was washed twice with PBS. RIPA (Beyotime Institute of Biotechnology) lysis buffer was added, and the supernatant was collected after centrifugation $\left(4^{\circ} \mathrm{C} ; 10,000 \mathrm{x} \mathrm{g} ; 5 \mathrm{~min}\right)$. Protein quantification was performed using a bicinchoninic acid assay kit (Thermo Fisher Scientific, Inc.). Loading buffer was mixed with protein and the mixture was boiled for $3 \mathrm{~min}$. Subsequently, proteins (10 $\mu \mathrm{l}$ per lane) were separated by SDS-PAGE on $10 \%$ gels for $90 \mathrm{~min}$, and transferred to a polyvinylidene fluoride film (Bio-Rad Laboratories, Inc.) at a temperature of $4^{\circ} \mathrm{C}$. The membrane was blocked with $5 \%$ skim milk powder in TBS with Tween-20 (TBST) for $1 \mathrm{~h}$ at $24^{\circ} \mathrm{C}$. Antibodies against Cas 3 (cat. no. 9665T; Cell Signaling Technology, Inc.; 1:1,000), cleaved Cas3 (cat. no. 9664T; Cell Signaling Technology, Inc.; 1:1,000), Cas9 (cat. no. 9508T; Cell Signaling Technology, Inc.; 1:1,000), cleaved Cas9 (cat. no. 7237T; Cell Signaling Technology, Inc.; 1:1,000) and $\beta$-actin (cat. no. TA-09; OriGene Technologies, Inc.; 1:1,000) were added and incubated overnight at $4^{\circ} \mathrm{C}$. The films were then washed three times with TBST, and secondary antibodies
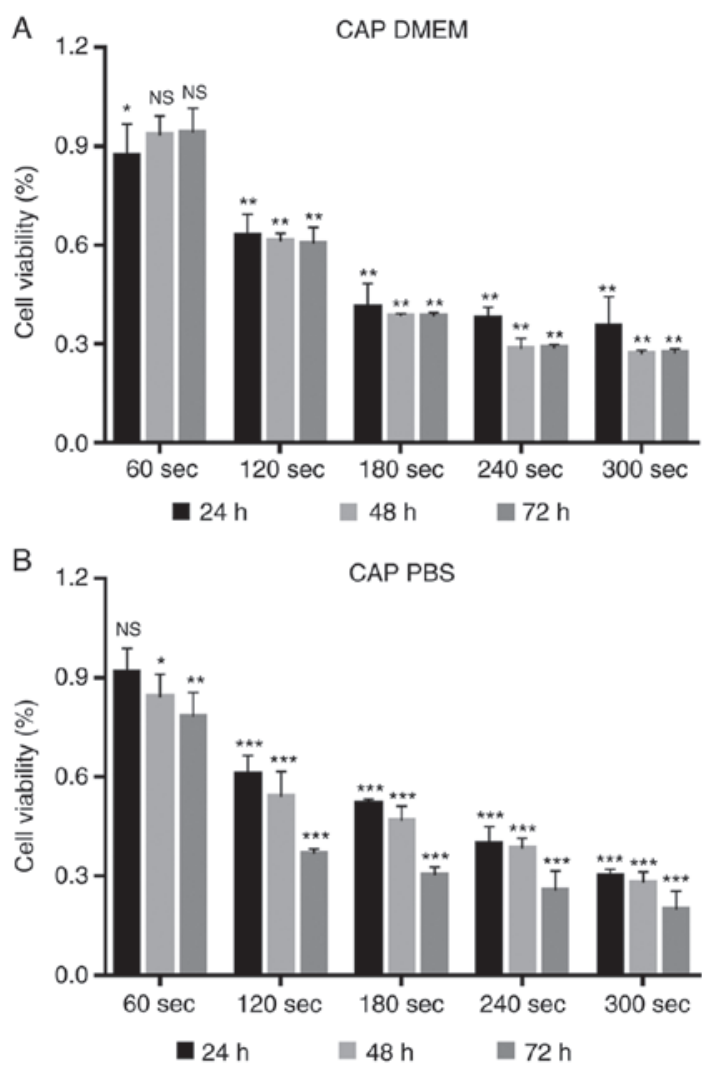

Figure 4. Cell viability of TE354T cells 24,48 and $72 \mathrm{~h}$ after receiving plasma-activated solution treatment based on the MTT assay. (A) TE354T cells were treated with CAP-activated DMEM, and cell viability was determined after 24,48 and $72 \mathrm{~h}$. (B) TE354T cells were treated with CAP-activated PBS under the same conditions, and the cell viability was determined. Cell viability of the control group was $100 \%$. Data are presented as the mean \pm SD of three independent experiments. ${ }^{*} \mathrm{P}<0.05,{ }^{* *} \mathrm{P}<0.01,{ }^{* * *} \mathrm{P}<0.001$ vs. respective con. CAP, cold atmospheric plasma; NS, not significant.

conjugated with horseradish peroxidase $(1: 10,000)$ were added for incubation for $1 \mathrm{~h}$ at room temperature. The secondary 


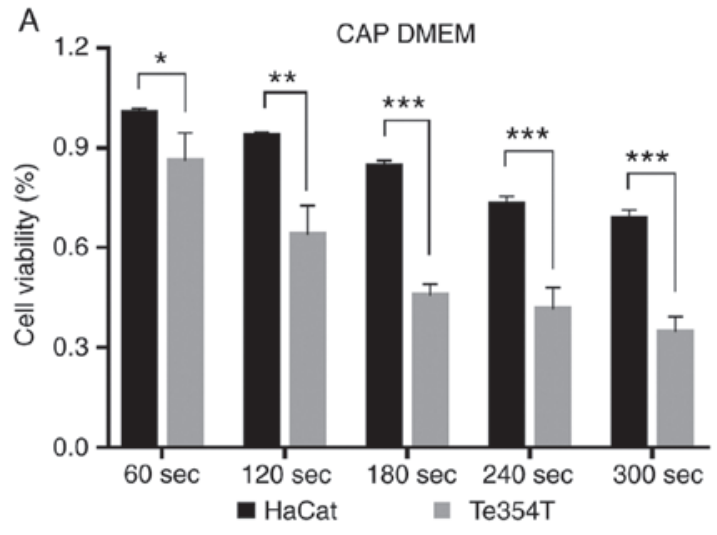

B

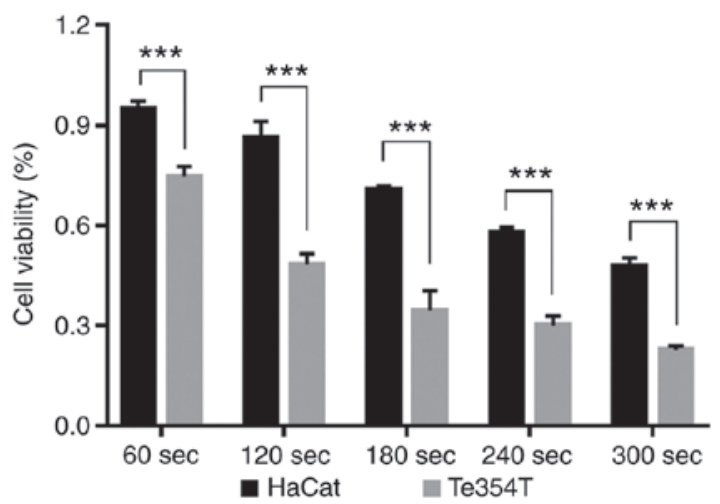

Figure 5. Survival rate of TE354T and HaCat cells treated with plasma-activated solution. (A) CAP-activated DMEM was used to treat both cell types, and the cell viability in the two groups was measured after $24 \mathrm{~h}$ of standard culture. (B) Both cell lines were treated with CAP-activated PBS, and the cell viability in the two groups was measured after $24 \mathrm{~h}$ of standard culture. Data are presented as the mean \pm SD of three independent experiments. ${ }^{~} \mathrm{P}<0.05$, ${ }^{* *} \mathrm{P}<0.01,{ }^{* * *} \mathrm{P}<0.001$. CAP, cold atmospheric plasma.

antibodies used for Cas3, cleaved Cas3 and cleaved Cas9 were goat rabbit anti-lgG (cat. no. ZB2301; OriGene Technologies, Inc.); the secondary antibodies used for Cas9 were goat mouse anti-IgG (cat. no. ZB2305; OriGene Technologies, Inc.). Signals were detected with using an enhanced chemiluminescence kit (Amersham ECL plus; GE Healthcare Life Sciences). $\beta$-actin (was used as an internal control. Density was analyzed using the Fino-do X6 analysis system (Tanon Science and Technology, Co., Ltd.). ImageJ software (v1.46; National Institutes of Health) was used to quantify the protein bands of interest.

RNA-seq. Cells were treated with PAS for 0,4 or $8 \mathrm{~h}$, followed by total RNA extraction using TRIzol ${ }^{\circledR}$ reagent (Invitrogen; Thermo Fisher Scientific, Inc.). The cell lysate was loaded into an RNase-free centrifuge tube and RNA-seq was performed by Shenzhen Huada Gene Technology Co., Ltd. The sequencing results and analysis of differential gene expression functions were performed by Shenzhen Huada Gene Technology Co., Ltd. The sequencing results were provided by Shenzhen Huada Gene Technology Co., Ltd. The analysis results report has not been shared to a public database at the time of publication.

Statistical analysis. Data are presented as the mean \pm SD of three independent experiments. Statistical significance was
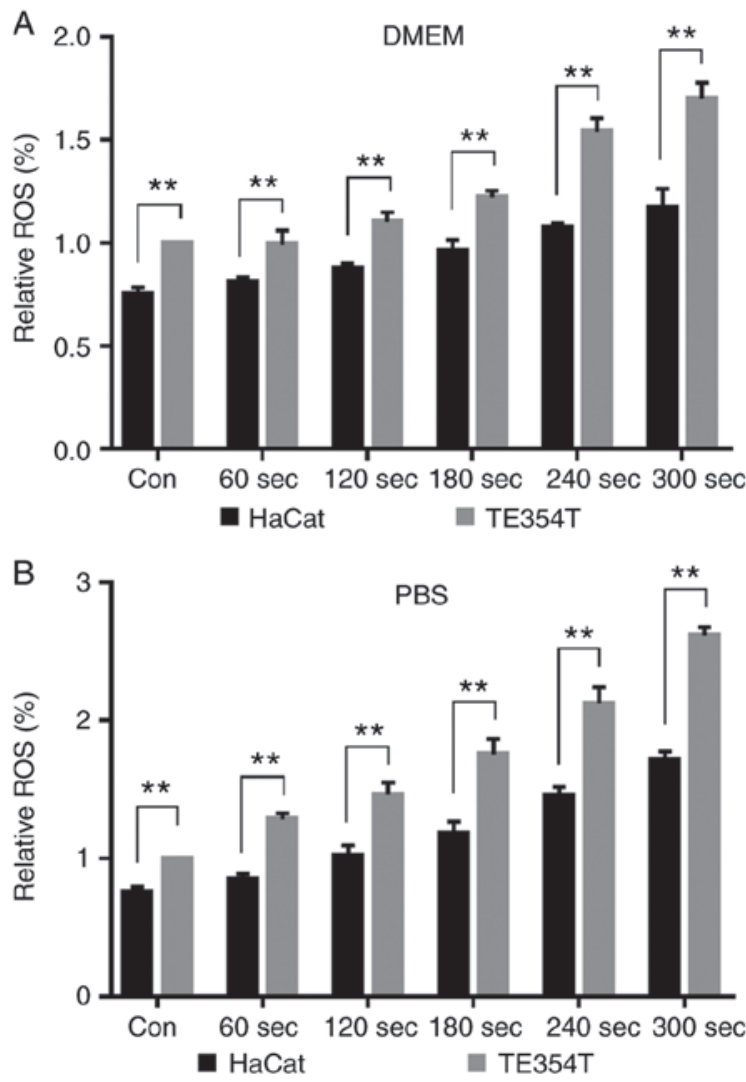

Figure 6. After plasma-activated solution treatment, cells were stained with dichloro-dihydro-fluorescein diacetate, and fluorescence was measured using a microplate reader to reflect changes in the levels of ROS in TE354T and HaCat cells. (A) Cells treated with CAP-activated DMEM. (B) Cells treated with CAP-activated PBS. Data are presented as the mean \pm SD of three independent experiments. ${ }^{* *} \mathrm{P}<0.01$. ROS, reactive oxygen species; $\mathrm{CAP}$, cold atmospheric plasma; con, control.

determined using an independent Student's t-test and ANOVA. Least Significant Difference post hoc test and Dunnett's post hoc test were used where appropriate. $\mathrm{P}<0.05$ was considered to indicate a statistically significant difference. Statistical analyses were performed using GraphPad Prism (version 5.01; GraphPad Software, Inc.) software.

\section{Results}

PAS leads to morphological changes in TE354T cells. Compared with untreated cells, cells treated with PAS for $6 \mathrm{~h}$ exhibited reduced intracellular volume and shrunken cell membranes. Furthermore, certain cells had detached from the bottom of the culture dish, and appeared small and round (Fig. 2). These effects became more apparent after treatment for $12 \mathrm{~h}$. Hoechst staining revealed bright blue cells after PAS treatment, indicating that the nucleus was condensed, and that the cells had begun to undergo apoptosis.

Evaluating the effect of PAS on BCC cell viability. Increased PAS treatment time resulted in a gradual decrease in the cell viability rate and this effect was more pronounced in the PBS group compared with the DMEM group (Fig. 3). Furthermore, plasma-activated DMEM and PBS stored for $24 \mathrm{~h}$ prior to treatment induced cell death. It is worth noting that after 

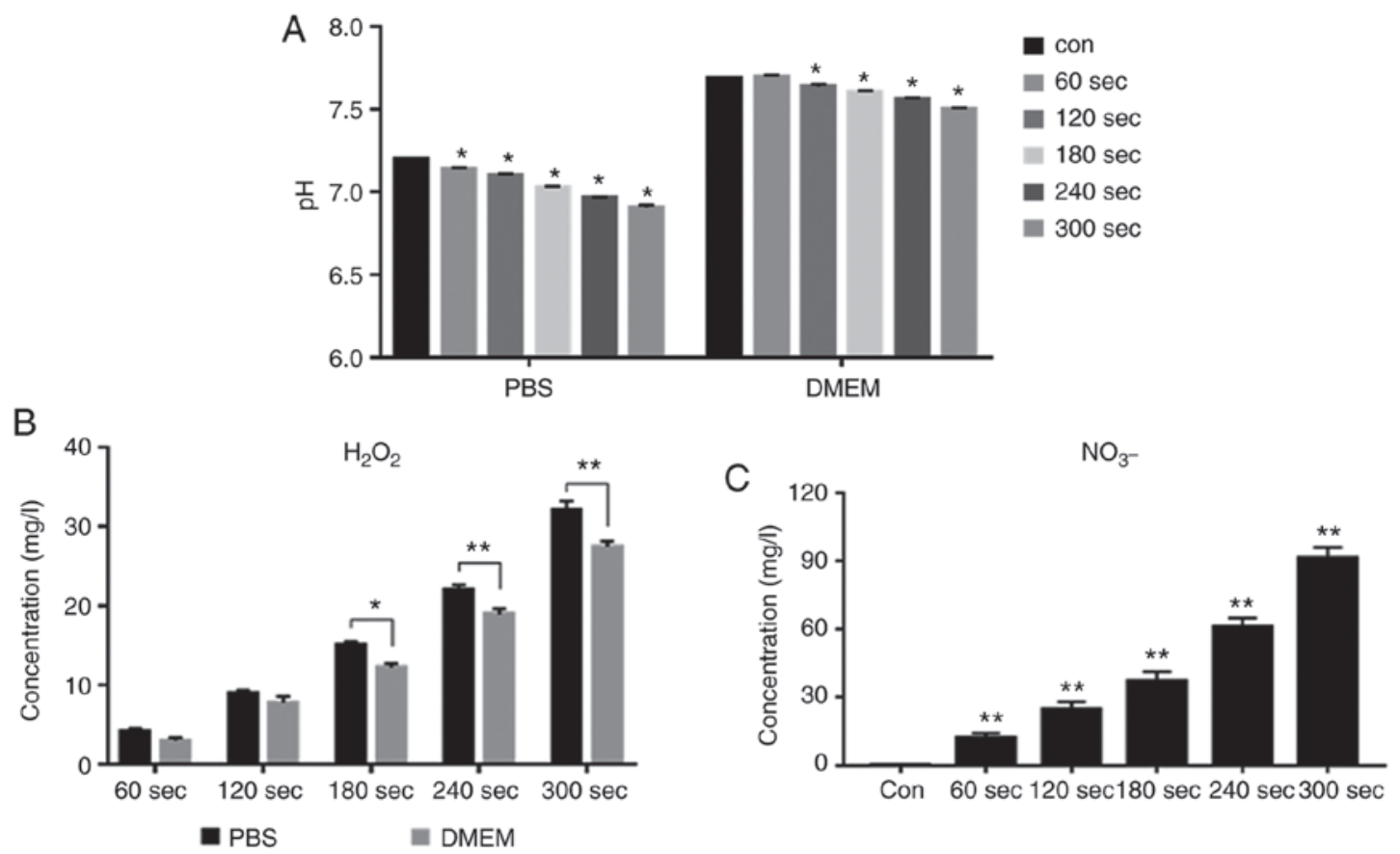

Figure 7. Detection of changes in reactive species and $\mathrm{pH}$ in cell-free solutions. (A) $\mathrm{pH}$ of the two groups of solutions did not change significantly after $\mathrm{CAP}$ treatment. " $\mathrm{P}<0.05$ vs. con. (B) $\mathrm{H}_{2} \mathrm{O}_{2}$ concentration in the two groups of solutions increased significantly, and this increase trend was more significant in the PBS solution. "P<0.05, ${ }^{* *} \mathrm{P}<0.01$. (C) Concentration of $\mathrm{NO}_{3}$ in PBS solution increased significantly with the increase of CAP treatment time. Data are presented as the mean $\pm \mathrm{SD}$ of three independent experiments. ${ }^{* *} \mathrm{P}<0.01$ vs. con. CAP, cold atmospheric plasma; con, control.

PAS storage for $24 \mathrm{~h}$, compared with the control group, the CAP-treated DMEM and PBS for 60 sec showed a proliferation-promoting effect on the cells.

As presented in Fig. 4, following treatment with PAS, TE354T cells were cultured for 24, 48 and $72 \mathrm{~h}$ under standard conditions. The survival rate of each group was then measured. It was observed that the proliferation of TE354T cells was inhibited within $72 \mathrm{~h}$ of PAS treatment. In the $300 \mathrm{sec}$ group, after TE354T cells were treated with CAP-activated DMEM and CAP-activated PBS, the cell survival rate was $\sim 30 \%$, and this inhibition continued to be significant for $72 \mathrm{~h}$. Furthermore, PAS demonstrated dose- and time-dependent inhibitory effects on the proliferation of TE354T cells.

PAS significantly decreased the proliferation of TE354T cells compared with HaCat cells (Fig. 5). In the absence of malignant epidermal keratinocytes, the viability of cells within the same groups was significantly higher than those of the BCC cell groups. In the DMEM group, even at the highest dose of PAS treatment, the survival rate of $\mathrm{HaCat}$ cells was $\sim 75 \%$, while that of TE354T cells in the same group was $<40 \%$. In the PBS group, this difference was less pronounced. Compared with DMEM, the apoptotic effect of PBS following plasma irradiation was stronger, but the selectivity was relatively weak.

Intracellular ROS levels are increased after PAS treatment. The intracellular ROS levels in HaCat and TE354T cells were examined before and after PAS treatment (Fig. 6). After treating cells with CAP-activated DMEM, ROS levels increased by $\sim 1.7$-fold in TE354T cells in the $300 \mathrm{sec}$ group, while those in HaCat cells only increased by $\sim 1$.4-fold. After treating cells with CAP-irradiated PBS, ROS levels in TE354T cells were increased by a maximum of $\sim 2.6$-fold. The basal ROS concentration in HaCat cells was lower than that in TE354T cells, and the increase in ROS levels in HaCat cells was lower after PAS treatment.

Reactive species in the solution increase and the $\mathrm{pH}$ decreases after CAP treatment. After 60, 120, 180, 240 and $300 \mathrm{sec}$ of CAP treatment, the pH of both DMEM and PBS solutions demonstrated a downward trend (Fig. 7A). After CAP treatment, $\mathrm{H}_{2} \mathrm{O}_{2}$ in both solutions increased. This growth trend was more pronounced in PBS solution after receiving CAP treatment at the same time. After $300 \mathrm{sec}$ of CAP treatment, the $\mathrm{H}_{2} \mathrm{O}_{2}$ concentration measured in PBS solution was $\sim 33 \mathrm{mg} / \mathrm{l}$. At the same time, it was $\sim 28 \mathrm{mg} / 1$ in DMEM (Fig. 7B). As the color of DMEM will affect the detection of $\mathrm{NO}_{3^{-}}$, only the change of $\mathrm{NO}_{3^{-}}$concentration in PBS solution after CAP treatment was measured. No $\mathrm{NO}_{3}-$ concentration was measured in the blank control group With the increase of CAP treatment time, the concentration of $\mathrm{NO}_{3}$ - in PBS solution increased (Fig. 7C). After $300 \mathrm{sec}$ of treatment, the measured $\mathrm{NO}_{3-}$ concentration in the solution was $\sim 90 \mathrm{mg} / \mathrm{l}$.

PAS induces apoptosis of BCC cells. Cell staining with Annexin V-FITC/PI can indicate the rate and time of apoptosis in cells. In the flow cytometry plots, the lower and upper right quadrants indicate early and late apoptosis, respectively. As presented in Fig. 8, the apoptotic rate was significantly increased following PAS treatment compared with the untreated control groups. Both early and late apoptosis exhibited an upward trend, which was more pronounced in the PBS-treated group. 

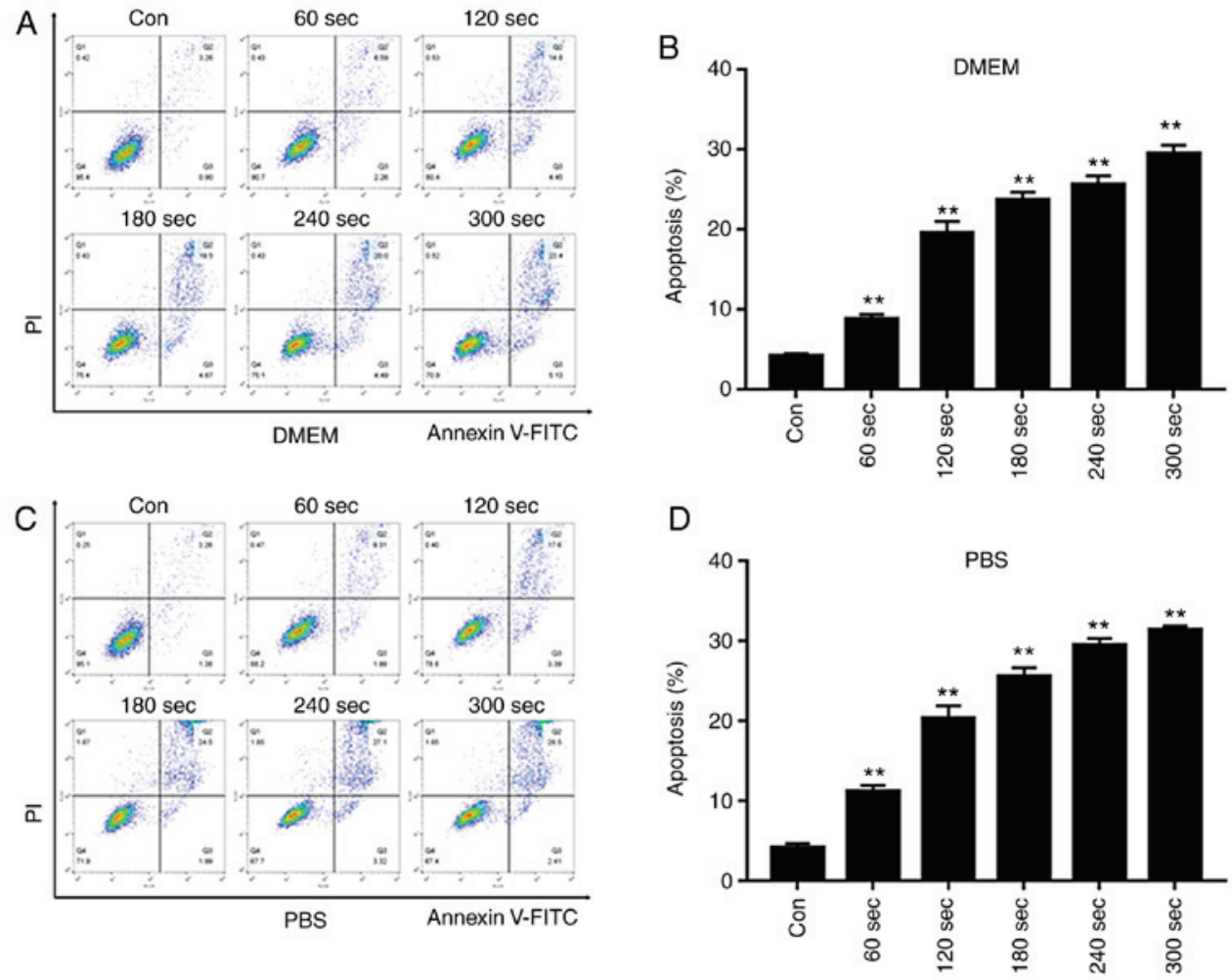

Figure 8. After receiving plasma-activated solution treatment, cell staining was performed using Annexin V-FITC/PI; the early and late apoptosis rates of the treated cells were measured by flow cytometry. (A) Flow cytometry showing apoptosis in cells treated with CAP-activated DMEM. In each of the small images, the lower left quadrant represents living cells, while the lower right quadrant and upper right quadrant represent early and late apoptotic cells, respectively. (B) Total apoptotic rate of different groups after CAP-irradiated DMEM treatment. (C) Flow cytometry showing apoptosis rates in cells treated with CAP-activated PBS. (D) Total apoptotic rate of the different groups after CAP-irradiated PBS treatment. Data are presented as the mean \pm SD of three independent experiments. ${ }^{* *} \mathrm{P}<0.01$ vs. con. CAP, cold atmospheric plasma; con, control; PI, propidium iodide.
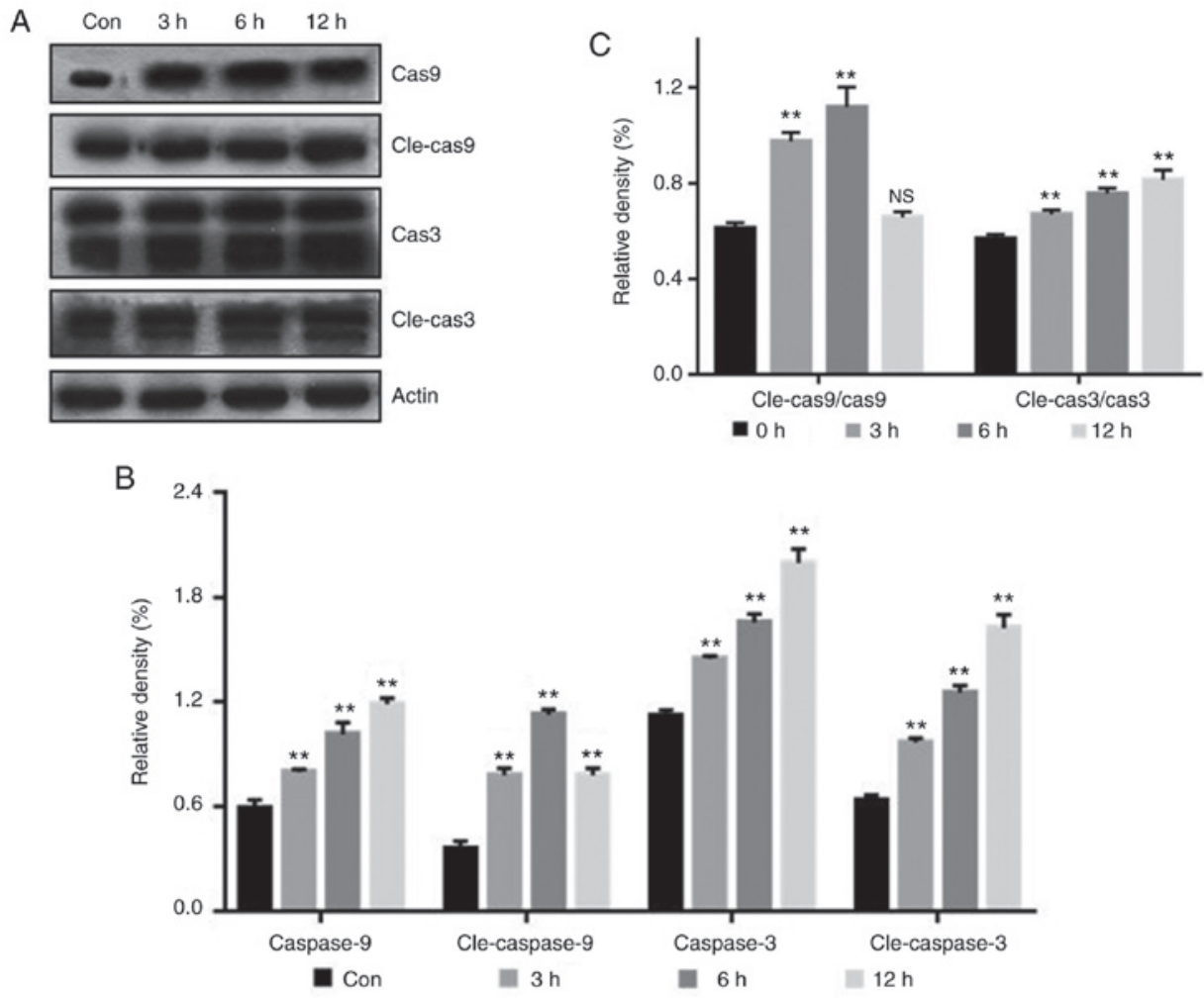

Figure 9. After 3, 6 and $12 \mathrm{~h}$ treatment with PAS, the expression of cas3/cle-cas3 and cas9/cle-cas9 in TE354T cells is analyzed by western blotting. Changes in cas3/cle-cas3 and cas9/cle-cas9 protein expression in TE354T cells after PAS treatment by (A) western blotting and (B) subsequent densitometry. ${ }^{* *} \mathrm{P}<0.01$ vs. respective con. (C) Changes in the ratio of cle-cas3/cas3 and cle-cas9/cas9 after PAS treatment. Data are presented as the mean \pm SD of three independent experiments. ${ }^{* *} \mathrm{P}<0.01$ vs. respective 0 h. PAS, plasma-activated solution; cas3, caspase 3; cle, cleaved; cas9, caspase 9; con, control; NS, not significant. 
A MA plot of CON-VS-Treat4h.DEGseq_Method

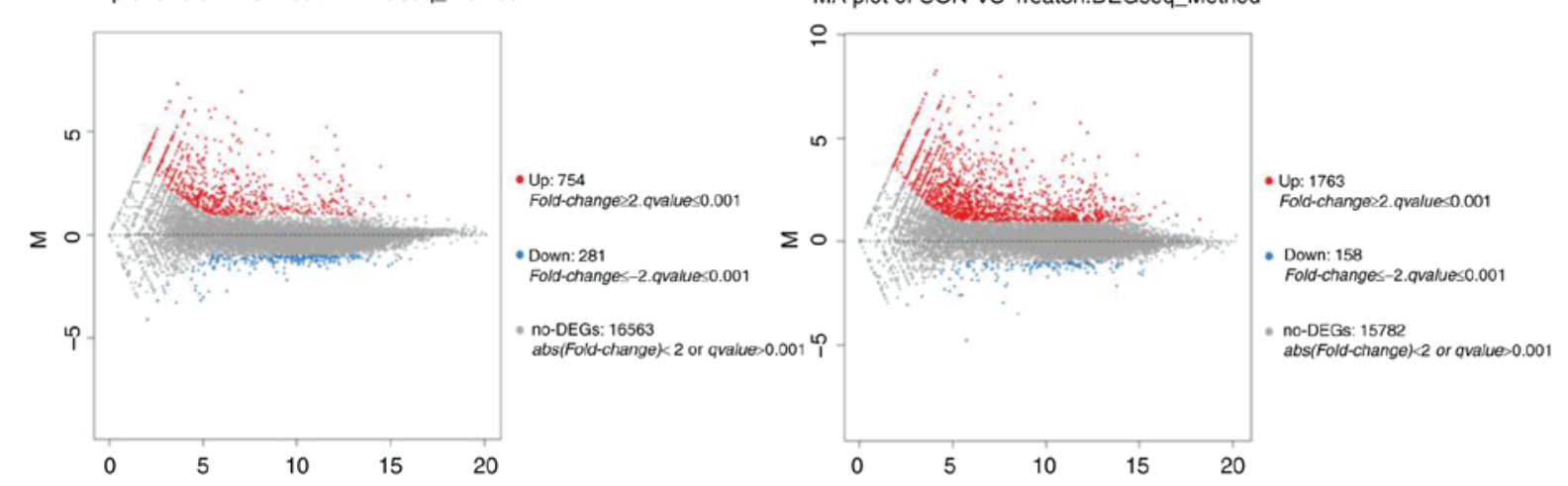

B DEGs number of the most enriched GOTerm
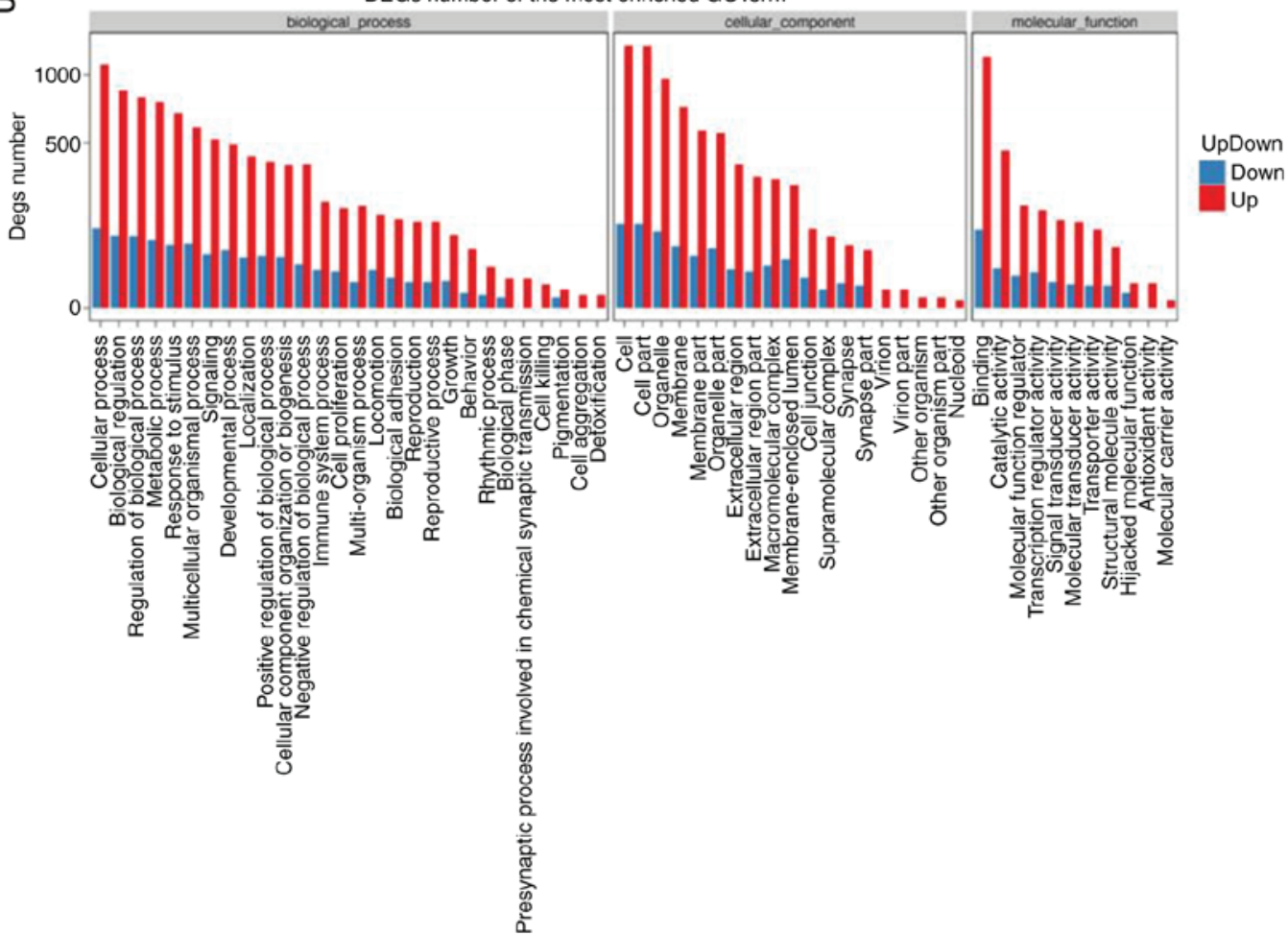

Figure 10. After treatment with PAS for 4 and 8 h, RNA-sequencing was performed on CON and treated cells to identify DEGs. (A) Scatter-plot distribution of DEGs after $4 \mathrm{~h}$ (left) or $8 \mathrm{~h}$ (right) PAS treatment. Red dots indicate differential genes that are upregulated, and the blue dots indicate differential genes that are downregulated. (B) GO functional classification of upregulated (red) and downregulated (blue) genes.

Western blot analysis of apoptosis-related protein expression. Cleaved-caspase (cle-cas) is the activated form of caspase (cas). The relative activity of cas 9 and cas 3 was significantly increased following PAS treatment, suggesting that PAS induced the intrinsic apoptotic pathway in TE354T cells. The ratio of cle-cas to cas was calculated, and the ratio increased significantly following PAS treatment. After $12 \mathrm{~h}$, the activity of cle-cas9 demonstrated a downward trend, possibly due to the necrosis of cells (Fig. 9).

Detection of PAS-induced apoptosis by RNA-seq. Differentially expressed genes (DEGs) were analyzed in untreated control cells and BCC cells stimulated with PAS for 4 or $8 \mathrm{~h}$. An increase in the expression of 754 genes, and a decrease in the expression of 281 genes, were observed after stimulation with PAS for $4 \mathrm{~h}$. After $8 \mathrm{~h}$, the number of upregulated DEGs increased to 1,763 (Fig. 10A). Based on these results, the genes were classified according to Gene Ontology (GO) terms: Molecular function, cellular component and biological process (Fig. 10B). Kyoto Encyclopedia of Genes and Genomes (KEGG) biological pathway classification and enrichment analysis was performed (Fig. 10C). Based on the degree of enrichment and the number of DEGs, 'MAPK signaling pathway', 'TNF signaling pathway' and 'IL-17 signaling pathway' were the KEGG pathways most significantly associated with PAS-induced apoptosis.

\section{Discussion}

Previous studies have typically used CAP to directly treat cells in standard culture. In this process, the active substance produced by CAP is first incubated with the liquid medium, ROS/RNS are dissolved in solution, and physical and chemical changes are induced by high concentrations of these 


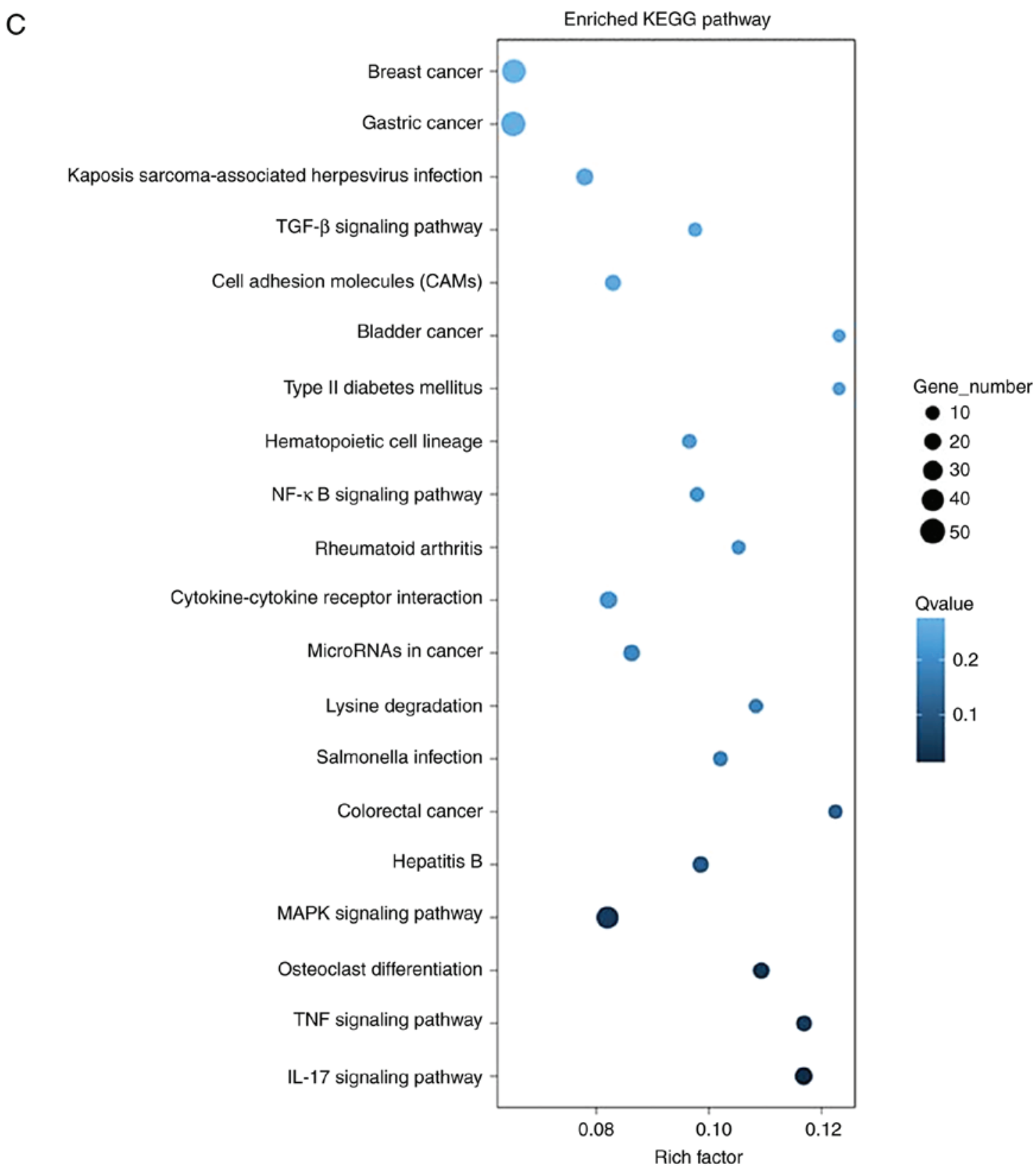

Figure 10. Continued. After treatment with PAS for 4 and 8 h, RNA-sequencing was performed on CON and treated cells to identify DEGs. (C) KEGG pathway enrichment results of DEGs. PAS, plasma-activated solution; DEGs, differentially expressed genes; GO, Gene Ontology; KEGG, Kyoto Encyclopedia of Genes and Genomes; CON, control.

components $(33,34)$. In the present study, CAP-activated PBS and DMEM solutions were prepared separately, in order to compare the effects of the two different activating fluids on BCC TE354T cells. PBS, which has a simple composition, more effectively inhibited the viability and promoted the apoptosis of TE354T cells following CAP treatment compared with DMEM. By contrast, the selective effect of PBS was not as prominent as DMEM when incubated with $\mathrm{HaCat}$ cells. The $\mathrm{H}_{2} \mathrm{O}_{2}$ concentration in the solution was found to be higher in the PBS solution under the same processing conditions. This may be associated with the simpler composition of the PBS solution. Yan et al (21) identified that cysteine and methionine in solution are the main factors leading to the inactivation of active substances. However, due to the absence of these specific amino acids, fewer physical and chemical changes in PBS were observed after CAP treatment, suggesting that it exerts more potent anticancer activity and can be stored for longer periods. This phenomenon is consistent with the results observed in the present study.

As a new strategy for cancer therapy, the shelf life of PAS presents a challenge that needs to be addressed. The effects of two PAS samples after $24 \mathrm{~h}$ storage and those of two fresh PAS samples were compared in the present study. After storage at $4^{\circ} \mathrm{C}$, both fresh and aged PAS inhibited TE354T cell viability after $24 \mathrm{~h}$. It is worth noting that after $24 \mathrm{~h}$ of storage, the group with the lowest exposure time exhibited increased cell viability. In previous studies, low doses of CAP were demonstrated to promote cell proliferation and wound healing $(35,36)$. In our previous study, plasma-activated medium successfully inhibited the proliferation of TE354T 
and human skin squamous cell carcinoma A431 cells after storage for 2 weeks at room temperature $\left(\sim 28^{\circ} \mathrm{C}\right), 4^{\circ} \mathrm{C}$ and $-20^{\circ} \mathrm{C}$ (Yang et al, unpublished).

Increased intracellular ROS is the most common cellular response to CAP treatment $(18,37,38)$. However, the magnitude of this increase may differ based on a phenomenon known as CAP selective action $(39,40)$. ROS is an important intracellular secondary messenger under normal physiological conditions. However, under pathological conditions, when intracellular ROS accumulation is excessive or the intracellular ROS scavenging system is damaged, it can cause damage to intracellular macromolecules, leading to a series of changes that ultimately induce necrosis or apoptosis $(41,42)$. In the present study, ROS levels in TE354T cells increased in a time-dependent manner after incubation with CAP-irradiated solution. This increase corresponded to the rate of necrotic apoptosis in the cells. Furthermore, under the same conditions, the increase in ROS in TE354T cells was higher than that in HaCat cells. Previous studies have suggested that hydrogen peroxide, hydroxyl radical and the peroxide ion are the main ROS produced by incubation with CAP $(14,43,44)$. As the active substance from which CAP originates is a polar or charged ion, specific channels and transport proteins on the cell membrane are required for the transmembrane diffusion of these activated substances $(45,46)$. Previous studies demonstrated that an increased number of aquaporins on the surface of cancer cells are the main cause of this significant increase in intracellular ROS levels $(47,48)$. This helps to explain why the ROS levels in TE354T cells were higher than those in HaCat cells under the same conditions.

It is now well known that after CAP treatment, apoptotic pathways are triggered by DNA and mitochondrial damage in cancer cells (39). RNA-seq technology was used to identify DEGs in TE354T cells before and after PAS treatment in the present study. The TNF and MAPK signaling pathways were significantly upregulated in TE354T cells after PAS stimulation. These two pathways are major pathways associated with cancer cell apoptosis $(26,49)$. Ishaq et al (26) investigated CAP-treated malignant melanoma cells and identified that the TNF receptor-based apoptotic pathway was activated by an increase in intracellular ROS. Xiang et al (49) identified that the MAPK signaling pathway plays a major role in the apoptosis of breast cancer cells induced by low temperature plasma. The hypothesis is that after ROS stimulation, the cells immediately develop DNA damage, particularly DNA DSBs. ATM is an important marker of DSBs that activates several cell cycle arrest-associated factors, including p53, as well as the expression of apoptotic signals through phosphorylation (28). Activation of the MAPK signaling pathway and the release of cytochrome $\mathrm{c}$ into the mitochondria lead to activation of the caspase family (49), which ultimately induced apoptosis in TE354T cells in the present study. Whether this effect is observed in all cancer cells treated with CAP requires further verification.

In the present study, CAP-irradiated DMEM and PBS inhibited the viability and promoted the apoptosis of BCC TE354T cells. This phenomenon was most likely due to an increase in intracellular ROS levels. Using RNA-seq technology, the TNF and MAPK signaling pathways were identified to be upregulated, and may play an important role in mediating cell necrosis and apoptosis. The results obtained in the present study provided a theoretical basis for the further study of the anticancer mechanisms of CAP.

\section{Acknowledgements}

The authors would like to thank Dr Xianbin Cao and Dr Pengbo Wen (Anhui Province Key Laboratory of Environmental Toxicology \& Pollution Control Technology, Hefei Institutes of Physical Science, Chinese Academy of Sciences) for their help in related experiments.

\section{Funding}

The present study was supported by The Foundation of The Second Affiliated Hospital of Anhui Medical University (grant no. 2015hhjh04); The National Natural Science Foundation of China (grant nos. 51777206, 31600680, 81673099, 31670860, 81602083 and 31800702); Anhui Provincial Natural Science Foundation (grant nos. 1608085QH216 and 1708085MA13); and Grants for Scientific Research of BSKY (grant no. XJ201505) from Anhui Medical University.

\section{Availability of data and materials}

The datasets used and/or analyzed during the current study are available from the corresponding author on reasonable request.

\section{Authors' contributions}

This study was conceived and designed by CY. The main experiment was conducted by XY, LW and ZC. YW also conducted some experiments. As an expert in the field of cold atmospheric plasma, CC proposed the concept of this study together with $\mathrm{CY}$ and participated in the drafting of the manuscript. YZ contributed to the experimental design of the present study, and analyzed the experimental data during the experiment. GZ participated in the completion of apoptotic cell flow detection, western blotting, RNA sequencing and other related experiments, and made significant contributions to the analysis and interpretation of experimental data.

\section{Ethics approval and consent to participate}

Not applicable.

\section{Patient consent for publication}

Not applicable.

\section{Competing interests}

The authors declare that they have no competing interests.

\section{References}

1. Verkouteren JAC, Ramdas KHR, Wakkee M and Nijsten T: Epidemiology of basal cell carcinoma: Scholarly review. Br J Dermatol 177: 359-372, 2017. 
2. Muzic JG, Schmitt AR, Wright AC, Alniemi DT, Zubair AS, Olazagasti Lourido JM, Sosa Seda IM, Weaver AL and Baum CL: Incidence and trends of basal cell carcinoma and cutaneous squamous cell carcinoma: A population-based study in olmsted county, minnesota, 2000 to 2010. Mayo Clin Proc 92: 890-898, 2017.

3. Garcovich S, Colloca G, Sollena P, Andrea B, Balducci L, Cho WC, Bernabei R and Peris K: Skin cancer epidemics in the elderly as an emerging issue in geriatric oncology. Aging Dis 8: 643-661, 2017.

4. Pyne JH, Myint E, Barr EM, Clark SP, David M, Na R and Hou R: Superficial basal cell carcinoma: A comparison of superficial only subtype with superficial combined with other subtypes by age, sex and anatomic site in 3150 cases. J Cutan Pathol 44 677-683, 2017.

5. Lipson EJ, Lilo MT, Ogurtsova A, Esandrio J, Xu H, Brothers P, Schollenberger M, Sharfman WH and Taube JM: Basal cell carcinoma: PD-L1/PD-1 checkpoint expression and tumor regression after PD-1 blockade. J Immunother Cancer 5: 23, 2017.

6. Mandel VD, Arginelli F, Pellacani G and Greco M: Combined carbon dioxide laser with photodynamic therapy for the treatment of nodular and infiltrative basal cell carcinoma. G Ital Dermatol Venereol 152: 672-674, 2017.

7. Wong CS, Strange RC and Lear JT: Basal cell carcinoma. BMJ 327: 794-798, 2003.

8. Kim SJ and Chung TH: Cold atmospheric plasma jet-generated RONS and their selective effects on normal and carcinoma cells. Sci Rep 6: 20332, 2016.

9. Rashmei Z, Bornasi $\mathrm{H}$ and Ghoranneviss M: Evaluation of treatment and disinfection of water using cold atmospheric plasma. J Water Health 14: 609-616, 2016.

10. Heinlin J, Morfill G, Landthaler M, Stolz W, Isbary G, Zimmermann JL, Shimizu T and Karrer S: Plasma medicine: Possible applications in dermatology. J Dtsch Dermatol Ges 8: 968-976, 2010 (In English, German).

11. Wang M, Holmes B, Cheng X, Zhu W, Keidar M and Zhang LG: Cold atmospheric plasma for selectively ablating metastatic breast cancer cells. PLoS One 8: e73741, 2013.

12. Keidar M, Walk R, Shashurin A, Srinivasan P, Sandler A, Dasgupta S, Ravi R, Guerrero-Preston R and Trink B: Cold plasma selectivity and the possibility of a paradigm shift in cancer therapy. Br J Cancer 105: 1295-1301, 2011.

13. Ratovitski EA, Cheng X, Yan D, Sherman JH, Canady J, Trink B and Keidar M: Anti-cancer therapies of 21st century: Novel approach to treat human cancers using cold atmospheric plasma. Plasma Proc Polymers 11: 1128-1137, 2014.

14. Kalghatgi S, Kelly CM, Cerchar E, Torabi B, Alekseev O, Fridman A, Friedman G and Azizkhan-Clifford J: Effects of non-thermal plasma on mammalian cells. PLoS One 6: e16270, 2011.

15. Kaushik NK, Kaushik N, Park D and Choi EH: Altered antioxidant system stimulates dielectric barrier discharge plasma-induced cell death for solid tumor cell treatment. PLoS One 9: e103349, 2014

16. Vandamme M, Robert E, Lerondel S, Sarron V, Ries D, Dozias S, Sobilo J, Gosset D, Kieda C, Legrain B, Pouvesle JM and Pape AL: ROS implication in a new antitumor strategy based on non-thermal plasma. Int J Cancer 130: 2185-2194, 2012.

17. Wang L, Yang X, Yang C, Gao J, Zhao Y, Cheng C, Zhao G and Liu S: The inhibition effect of cold atmospheric plasma-activated media in cutaneous squamous carcinoma cells. Future Oncol 15: 495-505, 2019

18. Sun JK, Joh HM and Chung TH: Production of intracellular reactive oxygen species and change of cell viability induced by atmospheric pressure plasma in normal and cancer cells. Appl Phys Lett 103: 153705, 2013.

19. Ishaq M, Evans MD and Ostrikov KK: Atmospheric pressure gas plasma-induced colorectal cancer cell death is mediated by Nox2-ASK1 apoptosis pathways and oxidative stress is mitigated by Srx-Nrf2 anti-oxidant system. Biochim Biophys Acta 1843 2827-2837, 2014

20. Nguyen NH, Park HJ, Yang SS, Choi KS and Lee JS: Anti-cancer efficacy of nonthermal plasma dissolved in a liquid, liquid plasma in heterogeneous cancer cells. Sci Rep 6: 29020, 2016.

21. Yan D, Nourmohammadi N, Bian K, Murad F, Sherman JH and Keidar M: Stabilizing the cold plasma-stimulated medium by regulating medium's composition. Sci Rep 6: 26016, 2016.

22. Yan D, Sherman JH, Cheng X, Ratovitski E, Canady J and Keidar M: Controlling plasma stimulated media in cancer treatment application. Appl Phys Lett 105: 224101, 2014.
23. Adachi T, Tanaka H, Nonomura S, Hara H, Kondo S and Hori M: Plasma-activated medium induces A549 cell injury via a spiral apoptotic cascade involving the mitochondrial-nuclear network. Free Radic Biol Med 79: 28-44, 2015.

24. Tanaka H, Nakamura K, Mizuno M, Ishikawa K, Takeda K, Kajiyama H, Utsumi F, Kikkawa F and Hori M: Non-thermal atmospheric pressure plasma activates lactate in Ringer's solution for anti-tumor effects. Sci Rep 6: 36282, 2016.

25. Yan D, Cui H, Zhu W, Nourmohammadi N, Milberg J, Zhang LG, Sherman JH, Keidar M: The specific vulnerabilities of cancer cells to the cold atmospheric plasma-stimulated solutions. Sci Rep 7: 4479, 2017.

26. Ishaq M, Kumar S, Varinli H, Han ZJ, Rider AE, Evans MD, Murphy AB and Ostrikov K: Atmospheric gas plasma-induced ROS production activates TNF-ASK1 pathway for the induction of melanoma cancer cell apoptosis. Mol Biol Cell 25: 1523-1531, 2014.

27. Keidar M: Plasma for cancer treatment. Post Communist Economies 24: 2015

28. Xu H, Klas M, Liu Y, Stack MS and Ptasinska S: DNA damage in oral cancer cells induced by nitrogen atmospheric pressure plasma jet. Appl Phys Lett 102: 644-654, 2013.

29. Chang JW, Kang SU, Shin YS, Kim KI, Seo SJ, Yang SS, Lee JS, Moon E, Baek SJ, Lee K and Kim CH: Non-thermal atmospheric pressure plasma induces apoptosis in oral cavity squamous cell carcinoma: Involvement of DNA-damage-triggering sub-G(1) arrest via the ATM/p53 pathway. Arch Biochem Biophys 545: 133-140, 2014.

30. Utaipan T, Athipornchai A, Suksamrarn A, Chunsrivirot S and Chunglok W: Isomahanine induces endoplasmic reticulum stress and simultaneously triggers p38 MAPK-mediated apoptosis and autophagy in multidrug-resistant human oral squamous cell carcinoma cells. Oncol Rep 37: 1243-1252, 2017.

31. Menon MB, Gropengießer J, Fischer J, Novikova L, Deuretzbacher A, Lafera J, Schimmeck H, Czymmeck N, Ronkina N, Kotlyarov A, et al: p38MAPK/MK2-dependent phosphorylation controls cytotoxic RIPK1 signalling in inflammation and infection. Nat Cell Biol 19: 1248-1259, 2017.

32. Nadeem A, Ahmad SF, Al-Harbi NO, Fardan AS, El-Sherbeeny AM, Ibrahim KE and Attia SM: IL-17A causes depression-like symptoms via $\mathrm{NF \kappa B}$ and p38MAPK signaling pathways in mice: Implications for psoriasis associated depression. Cytokine 97: 14-24, 2017.

33. Kang SU, Cho JH, Chang JW, Shin YS, Kim KI, Park JK, Yang SS, Lee JS, Moon E, Lee K and Kim CH: Nonthermal plasma induces head and neck cancer cell death: The potential involvement of mitogen-activated protein kinase-dependent mitochondrial reactive oxygen species. Cell Death Dis 5: e1056, 2014.

34. Tanaka H, Mizuno M, Toyokuni S, Maruyama S, Kodera Y, Terasaki H, Adachi T, Kato M, Kikkawa F and Hori M: Cancer therapy using non-thermal atmospheric pressure plasma with ultra-high electron density. Phys Plasmas 22: 391-400, 2015.

35. Arndt S, Unger P, Berneburg M, Bosserhoff AK and Karrer S: Cold atmospheric plasma (CAP) activates angiogenesis-related molecules in skin keratinocytes, fibroblasts and endothelial cells and improves wound angiogenesis in an autocrine and paracrine mode. J Dermatol Sci 89: 181-190, 2018.

36. Haertel B, von Woedtke T, Weltmann KD and Lindequist U: Non-thermal atmospheric-pressure plasma possible application in wound healing. Biomol Ther (Seoul) 22: 477-490, 2014.

37. Bekeschus S, Kolata J, Winterbourn C, Kramer A, Turner R, Weltmann KD, Bröker B and Masur K: Hydrogen peroxide: A central player in physical plasma-induced oxidative stress in human blood cells. Free Radical Res 48: 542-549, 2014.

38. Yan D, Talbot A, Nourmohammadi N, Sherman JH, Cheng X and Keidar M: Toward understanding the selective anticancer capacity of cold atmospheric plasma-a model based on aquaporins (Review). Biointerphases 10: 40801, 2015.

39. Yan D, Sherman JH and Keidar M: Cold atmospheric plasma, a novel promising anti-cancer treatment modality. Oncotarget 8: 15977-15995, 2017

40. Canal C, Fontelo R, Hamouda I, Guillem-Marti J, Cvelbar U and Ginebra MP: Plasma-induced selectivity in bone cancer cells death. Free Radic Biol Med 110: 72-80, 2017

41. Zhao S, Xiong Z, Xiang M, Meng D, Lei Q, Li Y, Deng P, Chen M, Tu M, Lu X, et al: Atmospheric pressure room temperature plasma jets facilitate oxidative and nitrative stress and lead to endoplasmic reticulum stress dependent apoptosis in HepG2 cells. PLoS One 8: e73665, 2013. 
42. Arjunan KP and Clyne AM: Non-thermal dielectric barrier discharge plasma induces angiogenesis through reactive oxygen species. Conf Proc IEEE Eng Med Biol Soc 2011: 2447-2450, 2011.

43. Sun JK, Chung TH, Bae SH and Leem SH: Induction of apoptosis in human breast cancer cells by a pulsed atmospheric pressure plasma jet. Appl Phys Lett 97: 23702, 2010.

44. Yan D, Talbot A, Nourmohammadi N, Cheng X, Canady J, Sherman J and Keidar M: Principles of using cold atmospheric plasma stimulated media for cancer treatment. Sci Rep 5: 18339, 2015.

45. Almasalmeh A, Krenc D, Wu B and Beitz E: Structural determinants of the hydrogen peroxide permeability of aquaporins. FEBS J 281: 647-656, 2014.

46. Bienert GP and Chaumont F: Aquaporin-facilitated transmembrane diffusion of hydrogen peroxide. Biochim Biophys Acta 1840: 1596-1604, 2014.
47. Kawasaki T, Kusumegi S, Kudo A, Sakanoshita T, Tsurumaru T, Sato A, Uchida G, Koga K and Shiratani M: Effects of irradiation distance on supply of reactive oxygen species to the bottom of a Petri dish filled with liquid by an atmospheric O2/He plasma jet. J Appl Phys 119: 173301, 2016.

48. Miller EW, Dickinson BC and Chang CJ: Aquaporin-3 mediates hydrogen peroxide uptake to regulate downstream intracellular signaling. Proc Natl Acad Sci USA 107: 15681-15686, 2010.

49. Xiang L, Xu X, Zhang S, Cai D and Dai X: Cold atmospheric plasma conveys selectivity on triple negative breast cancer cells both in vitro and in vivo. Free Radic Biol Med 124: 205-213, 2018 